\title{
High occupancy vehicle (HOV) lanes as a means of transport demand management: the Thessaloniki experience
}

\author{
S. Basbas \\ Department of Transportation and Hydraulic Engineering, \\ Faculty of Rural and Surveying Engineering, School of Technology, \\ Aristotle University of Thessaloniki, Greece
}

\begin{abstract}
Transport Demand Management (TDM) measures are used worldwide as a means to reduce traffic and environmental impact in congested areas. These measures affect travel behavior in such a way as to promote sustainable mobility. One of the TDM measures is the High Occupancy Vehicles (HOV) lane. In the framework of this paper an attempt has been made to present three case studies concerning the evaluation of HOV lanes hypothetical scenarios in the city of Thessaloniki, Greece. The evaluation has been made through the use of modeling techniques and the results are expressed in terms of traffic and environmental indicators. HOV lanes have been proved to be, in principal, an efficient tool for managing transport demand but there is need for further examination of the environmental impact.
\end{abstract}

Keywords: transportation demand management (TDM), high occupancy vehicles (HOV) lane, transport modelling, environmental impact.

\section{Introduction}

Traffic and environmental problems characterize most of the cities all over the world. The provision of new infrastructure is not always a solution due to the high cost it imposes to the society. The promotion of environment friendly transport plans seems to be the most appropriate step for many local authorities. This target can only be achieved if the proposed measures can affect modal split in favour of Public Transport, bicycles and walking. Transport Demand Management (TDM) measures are used in order to reduce the use of private cars 
in congested areas and at the same time to promote sustainable mobility. TDM "refers to various strategies that change travel behaviour (how, when and where people travel) in order to increase transport system efficiency and achieve specific objectives such as reduced traffic congestion, road and parking cost savings, increased safety, improved mobility for non-drivers, energy conservation and pollution emission reductions" [1]. High Occupancy Vehicles (HOV) lanes belong to the TDM measures. More specifically, HOV lanes belong to the supplementary measures according to the classification of TDM measures in the AIUTO project [2]. A HOV lane is a lane where private cars can enter only if an occupancy requirement is met (e.g., more than 2 or 3 passengers in the car). According to the Online TDM Encyclopedia [1] "HOV Priority is a major component of many regional TDM programs. HOV Priority refers to strategies that give priority to High Occupancy Vehicles (also called Ridershare Vehicles), including transit buses, vanpools and carpools. Two, three or four occupants (indicated as $2+, 3+$ or $4+$ ) may be required to be considered as HOV, depending on the circumstances".

The first HOV lane in the UK was introduced in 1998 on the A647 Stannigley Road and Stanningley By-Pass in the area of the cities of Leeds and Bradford [3]. Nowadays there are more than $200 \mathrm{HOV}$ lane projects in use on streets and highways worldwide [4]. The benefits from the introduction of HOV lanes depend on various parameters. In the EU project ICARO [5] demonstration site of Leeds, UK, where an HOV lane was introduced, the car occupancy rate increased from 1,35 to 1,41 and the total number of cars was decreased. The effects of new high-occupancy vehicle lanes on travel and emissions under the Federal Clean Air Act, the California Clean Air Act, and the Federal Surface Transportation Act are examined in a study in the U.S.A. [6]. Recommendations from this study include, among other things, the use of equilibrate travel impedances among all relevant model steps.

Dahlgren [7] suggests that "unless substantial delay remains on the general purpose lane after the HOV lane is constructed, there will be little incentive for travelers to shift from a single occupant vehicle to an HOV". The optimum number of HOV lanes in a given multilane highway can be determined through the use of a deterministic equilibrium model [8]. The implementation of a HighOccupancy Toll (HOT) lane (which is a HOV lane also serving drivers of low occupancy vehicles if they pay a toll) can reduce congestion under certain circumstances. Dahlgren also pointed out in his research [9] that concern about low utilization of HOV lanes (and therefore waste capacity) together with the revenue generated from HOT lanes led the respective authorities to seriously consider HOT lanes. The first HOT lane was implemented in 1995 on State Route 91 in Orange County, USA [9].

Within the framework of this paper the traffic and environmental impact of HOV lanes are evaluated through the use of a modelling technique having the city of Thessaloniki as a study area. The simulation model used in order to perform the evaluation of the hypothetical HOV lanes is the SATURN (Simulation and Assignment of Traffic to Urban Road Networks). 


\section{Transport system characteristics in the city of Thessaloniki}

Thessaloniki is the second biggest city in Greece and is situated in the north part of the country. The population of the prefecture of Thessaloniki includes 1.084.001 residents [10], the population of the Thessaloniki Greater Area (TGA) includes 800.764 residents and the population of the municipality of Thessaloniki (the biggest municipality in TGA) includes 385.406 residents. According to the Thessaloniki General Transportation Study (TGTS) a number of 1.600 .00 trips were made in 1998 on a daily basis in the city by all transport modes (compared to 1.350 .000 in the year 1988) of which 400.000 trips had at least one end in the city center $[11,12]$.

It is important to mention at this point that, according to the same source, $30,5 \%$ of those trips were made by private cars (as a driver) and $10,1 \%$ were made by private cars (as a passenger). That means that more than $40 \%$ of the total number of trips were made by private cars in contrast to the Public Transport share which is only $27,5 \%$. The respective figures for Athens include 8.000 .000 daily trips (year 2008 data) using all available transport modes of which (trips) $43 \%$ are made with the use of the extensive Public Transport network which includes metro, tram, buses, electric railway, trolley buses and the suburban trains.

The car ownership in TGA (number of passenger cars per 1.000 inhabitants) varies between 220 and 305 with an average value of 253 , while ten years before the respective value was 177 . According to the results of the traffic simulation model EMME/2, which was used in the framework of the TGTS, this figure will be in the area of 428 to 440 in the year 2014 [12].

The Public Transport (PT) system in the city consists of buses only. More specifically, the Thessaloniki Bus Operator (O.A.S.Th.) has a total number of 603 buses (year 2008 data) [13]. There are 73 bus lines carrying 180 million passengers per year. It must be mentioned that the city is characterized by serious traffic and associated environmental problems especially in its centre. This is the reason why major transport infrastructure projects are under construction (i.e. metro) or are expected to be constructed (i.e. submerged tunnel to bypass the city centre). In addition to the infrastructure transport projects the city authorities implemented a number of TDM measures like a network of four with-flow bus lanes (three of which cross the city center and the forth one has an outbound direction and it connects the city center with the eastern part of the city).

As far as parking policy is concerned, there are a significant number of onstreet places in the city center where a parking fee is imposed. Another important parameter in the parking policy is the provision of on-street parking places for the exclusive use of the residents of the city center.

Access to the city center is free of charge today for the drivers, although from time to time there is a discussion in the city about the need to implement some kind of measures for access control in order to face the excessive demand for trips. Another important parameter of the problem is that the average load factor of passenger cars is 1.2. In the framework of the last major home-based questionnaire survey in the city of Thessaloniki [12] interviewees were asked to 
state their opinion about various TDM measures including car pooling. As shown in Figure 1, the vast majority of people seem to be very much in favor of car pooling but no safe conclusion can be made from this result due to the fact that people will possibly react in a totally different way if such a measure is implemented. This is the main reason why such a measure has been considered with skepticism by the city authorities.

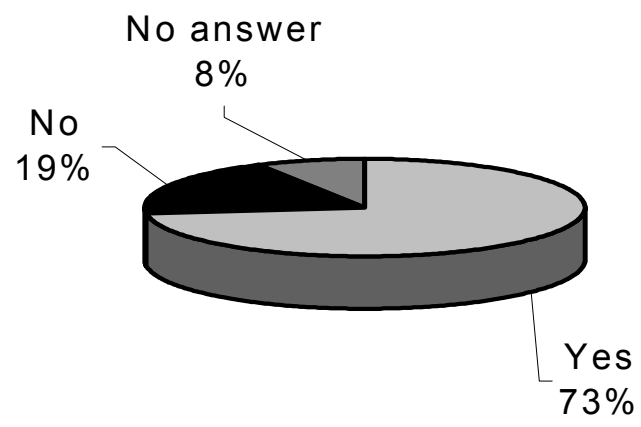

Figure 1: Citizens' response to the introduction of car-pooling. Source: [12].

Despite the fact that such a TDM measure is not foreseen for implementation in the near future, various research efforts took place in the framework of Aristotles' University of Thessaloniki or EU funded research projects concerning the examination of HOV lanes scenarios in the city through the use of modeling techniques. The results of three case studies concerning the investigation of these scenarios for the implementation of HOV lanes in the city of Thessaloniki are presented in the following sections.

\section{Case studies for HOV lanes in the city of Thessaloniki}

\subsection{HOV lane along Alexander the Great Avenue}

The first case study refers to the examination of a HOV lane in the eastern part of the city of Thessaloniki and took place in the framework of the EU project ICARO [14]. The HOV lane was chosen to be a contra-flow lane along the main one-way arterial road Alexander the Great Avenue (outbound direction) connecting the city centre with the eastern part of the city. The specific avenue became a two-direction road in the past in order to better serve traffic volumes which were directed to the city centre from the eastern part of the city (i.e. municipality of Kalamaria) but the project was cancelled after some time due to road safety problems.

The length of the HOV lane under examination was $3,5 \mathrm{~km}$. Three different scenarios were evaluated with the aid of the traffic simulation model SATURN. SATURN is a suite of flexible network analysis program developed at the 
Institution for Transport Studies, University of Leeds, UK. SATURN is a combined traffic simulation and assignment model for the analysis of traffic management schemes over relatively localised networks. The use of SATURN, as a tool to assess environmental and traffic impact, has been proved to be of great importance in various research efforts in Greece [15].

The first scenario includes the construction of the $3,5 \mathrm{~km}$ HOV lane only. In the second scenario a parking station is foreseen to be constructed at the entrance of the HOV lane in order to attract drivers who would like to be car poolers. Finally, both passenger cars and Public Transport buses use the HOV lane in the third scenario. The corridor-based travel time savings for the three scenarios (in minutes per hour for all vehicles) are presented in Table 1. It must be mentioned at this point that Queen Olga Avenue is the corridor which serves the traffic towards the city centre in the existing situation. The HOV lane is actually a corridor which is parallel to the corridor of Queen Olga avenue. As shown in Table 1, there are gains in terms of travel time, something that is a strong motive for those drivers who will use the HOV lane.

Table 1: Corridor-based travel time savings (in minutes per hour for all vehicles).

\begin{tabular}{|c|c|c|c|c|}
\hline Route & $\begin{array}{c}\text { Basic } \\
\text { scenario } \\
\text { (existing } \\
\text { situation) } \\
\text { Absolute } \\
\text { value }\end{array}$ & $\begin{array}{c}1^{\text {st }} \text { scenario } \\
\text { (HOV lane for } \\
\text { passenger } \\
\text { cars) }\end{array}$ & $\begin{array}{c}2^{\text {nd }} \text { scenario } \\
\text { (HOV lane }+ \\
\text { parking } \\
\text { station) }\end{array}$ & $\begin{array}{c}3^{\text {rd }} \text { scenario } \\
\text { (HOV lane for } \\
\text { passenger cars } \\
\text { and buses) }\end{array}$ \\
\hline $\begin{array}{c}\text { Queen Olga } \\
\text { Avenue }\end{array}$ & 15,9 & $1,05(6,6 \%)$ & $1,01(6,4 \%)$ & $1,18(7,4 \%)$ \\
\hline DOV & $\begin{array}{c}\text { Same as } \\
\text { above }\end{array}$ & $2,85(17,8 \%)$ & $2,68(16,8 \%)$ & $2,85(17,8 \%)$ \\
\hline
\end{tabular}

Source: [14].

According to the research results there was a reduction (from $0.9 \%$ to $3 \%$ ) in fuel consumption in the three scenarios. The third scenario proved to be the most preferable one in terms of fuel consumption. Emission levels $\left(\mathrm{CO}_{2}\right.$ and $\left.\mathrm{HC}\right)$ increased in the three scenarios (from $0.4 \%$ to $0.9 \%$ ).

It is also important to point out that passenger-hours decreased (from 1.4\% up to $4.1 \%$ ) with the third scenario to be the most preferable one. Finally, passenger-kilometres increased from $0.7 \%$ to $0.9 \%$ due to the fact that longer distances must be travelled in the road network by the drivers. 


\subsection{HOV lane along Tsimiski Str. (city center)}

The second case study concerns the examination of a scenario including the implementation of an HOV lane in the most heavily congested arterial street (Tsimiski Str.) in the central area of the city of Thessaloniki. The case study carried out in the framework of the research activities of the Faculty of Rural \& Surveying Engineering, Aristotle University of Thessaloniki [16].

This scenario is also evaluated with the aid of SATURN as in the previously presented case study. Figure 2 shows the whole Thessaloniki network used for the modeling purposes. Tsimiski Str. is a one-way, heavily congested, street with four lanes one of which is a bus lane. It serves traffic directed to the CBD as well as through traffic.

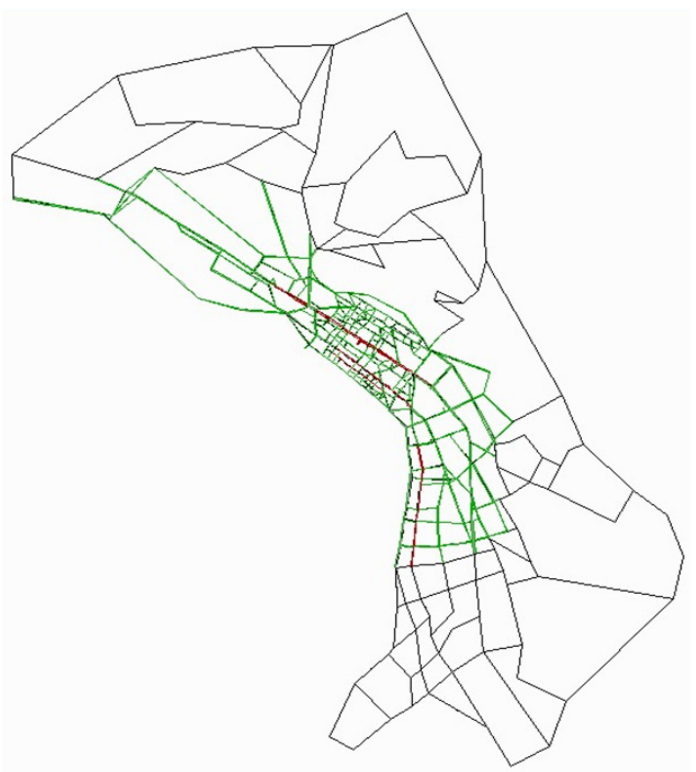

Figure 2: $\quad$ The Thessaloniki network.

Various parameters describing the performance and the level of service of Thessaloniki's central road network were examined through the use of SATURN. The values of the performance indicators were calculated for the road network "before" and "after" the implementation of the proposed HOV lane.

The parameters examined in this research include traffic volumes, speed, delays and the use of the road network expressed in travel distance (pcu*kms) and in travel time (pcu*hrs), where pcu is passenger car unit. Special consideration was given to the environmental impact of the proposed scheme, which were evaluated through the examination of the emission of pollutants and fuel consumption.

The results are based on the examination of the following two scenarios: a) "Before" scenario: Tsimiski Str. without HOV Lane (3 lanes for all vehicles), 
b) "After" scenario: Tsimiski Str. with HOV Lane (and 2 lanes for other vehicles).

Table 2 presents the values of indicators in the "before" and "after" situation for all types of vehicles (morning peak period) on Tsimiski Str. The average traffic volume (expressed in $\mathrm{pcu} / \mathrm{h}$ ) has decreased by $11,6 \%$ according to the results presented in this Table. It is also important to notice that the average speed has also decreased by 1,28\%. Delays (expressed in seconds) have decreased by $2,59 \%$ and the total fuel consumption (expresses in lt) has increased by $3,37 \%$.

Table 2: Values of indicators in the "before" and "after" situation for all types of vehicles (morning peak period) on Tsimiski Str.

\begin{tabular}{|c|c|c|c|c|c|}
\hline & $\begin{array}{c}\text { "Before" } \\
\text { Situation }\end{array}$ & $\begin{array}{c}\text { "After" } \\
\text { Situation }\end{array}$ & $\begin{array}{c}\text { Difference } \\
(\%)\end{array}$ & $\begin{array}{c}\text { HOV } \\
\text { Lane }\end{array}$ & $\begin{array}{c}\text { Difference } \\
(\%)\end{array}$ \\
\hline $\begin{array}{c}\text { Average Traffic } \\
\text { Volume (pcu/h) }\end{array}$ & 3.078 & 2.721 & $-11,60$ & 625 & - \\
\hline $\begin{array}{c}\text { Average Speed } \\
\text { (km/h) }\end{array}$ & 15,6 & 15,4 & $-1,28$ & 22,8 & 46,15 \\
\hline $\begin{array}{c}\text { Total Delays } \\
(\mathrm{sec})\end{array}$ & 618 & 602 & $-2,59$ & 515 & $-16,67$ \\
\hline $\begin{array}{c}\text { Total Fuel } \\
\text { Consumption } \\
\text { (lit) }\end{array}$ & 2.138 & 2.210 & 3,37 & 496 & - \\
\hline
\end{tabular}

Source: [16].

The evaluation showed that the environmental conditions in the city road network did not improve after the implementation of the examined HOV scheme. The same conclusion also applies in the case of the examination of the specific road segment (Tsimiski Str.) where the HOV lane was hypothetically implemented with the exception of $\mathrm{HC}$ values (these values are decreased in the "after" situation). Although the differences observed in the values of $\mathrm{CO}, \mathrm{CO}_{2}$, $\mathrm{NO}_{\mathrm{X}}, \mathrm{HC}$ and $\mathrm{Pb}$ in the "before" and "after" situation" are not very high, it seems that the environmental benefits from the implementation of the specific measure (HOV lane) are questionable. The results have also shown that drivers using the HOV lane experience fewer delays (in the area of 17\%).

\subsection{HOV lane along A. Svolou Str. (city center)}

In the framework of the research activities in the Faculty of Rural \& Surveying Engineering of the Aristotle University of Thessaloniki a scenario was evaluated concerning the implementation of an HOV lane along the road axis A. SvolouKeramopoulou-Ermou [17]. The specific road axis consists of three streets and connects the eastern with the western part of the city centre. Due to its relatively poor geometrical characteristics (one lane along Svolou Str. and Keramopoulou Str. and one lane per direction along Ermou Str. for traffic) it serves lower traffic 
volumes compared to Tsimiski Str. However, it plays an important role in the central network and this is the reason why a tramline was considered to pass through this axis in the past, but that project was never implemented. The HOV lane scenario was tested with the aid of the SATURN model as in the previous two case studies. Figure 3 presents the traffic flows in the "before" and "after" situation (Scenario 1 and Scenario 2 respectively). As shown in this figure there is a slight increase in the number of pcu in the "after" situation. Vehicle delays reduced by $142 \%$ in the "after" situation.

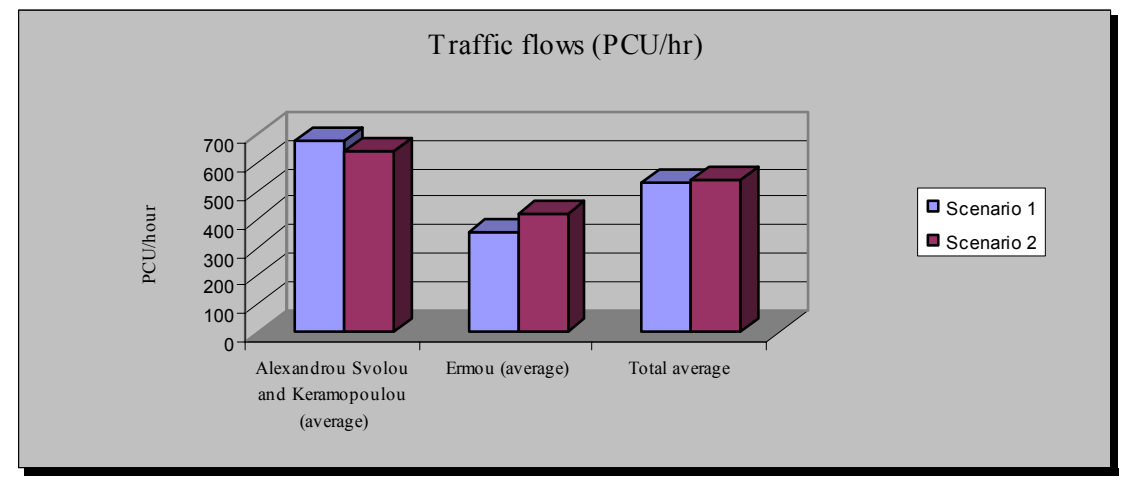

Figure 3: $\quad$ Traffic flows before and after the application of HOV lane.

As far as speed is concerned, Figure 4 shows that overall there is a substantial increase (from 18,7 to $24,6 \mathrm{~km} / \mathrm{h}$ ) in the "after" situation (scenario 2). The reduction in the values of the $\mathrm{CO}_{2}$ emissions in the "after" situation is also very significant $(-40 \%)$. Finally, energy saving in terms of fuel consumption is also very significant $(-39 \%)$.

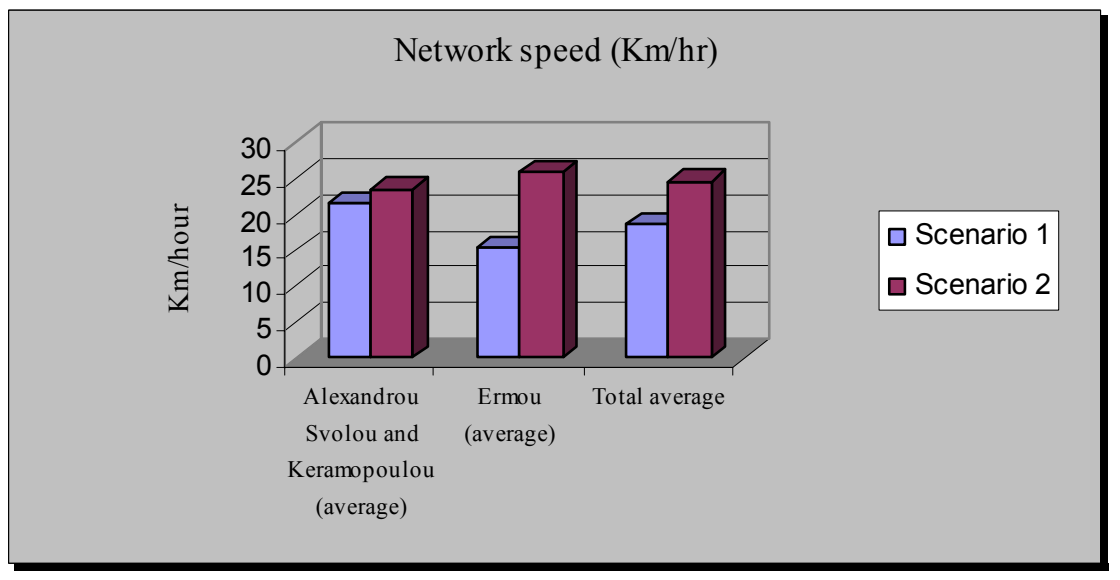

Figure 4: $\quad$ Speed $(\mathrm{Km} / \mathrm{hr})$ before and after the HOV lane. 


\section{Conclusions}

The conclusions raised from the examination of the three case studies vary, depending on a number of parameters. In the first case study (Alexander the Great Avenue) there was a reduction in fuel consumption in the three scenarios. Emission levels $\left(\mathrm{CO}_{2}\right.$ and $\left.\mathrm{HC}\right)$ seem to have increased in the three examined scenarios. What is the most important thing is the fact that drivers in the HOV lane experience time savings and they have the alternative solution to avoid congested roads towards the city center. The success of the fist case study is based, among other things, to the provision of park-n-ride facilities. However, longer distances have to be traveled by the drivers. In any case a parking station at the entrance of an HOV lane promotes the use of the specific lane and also the use of PT buses in cases where buses are allowed to use the HOV lane.

In Tsimiski Str. (second case study) both traffic volumes and vehicle speed reduced in the near area of the project, while vehicle speed increased in the HOV lane. No direct comparison can be made between the first and the second case study since the first one aims at the facilitation of drivers who are directed to the city center during peak hours while the second one mainly aims at the facilitation of through traffic (as far as the city center is concerned). In the third case study, vehicle delays significantly reduced in the "after" situation as well as the energy consumption and the $\mathrm{CO}_{2}$ emissions. Although the third case study also referred to a road axis in the city center, the basic role of this axis was to serve traffic directed to various areas in the city center and thus the benefits, in terms of absolute values, cannot be compared to those of Tsimiski Str. The evaluation showed that problems seem to appear when the whole road network is examined in the three case studies.

The implementation of an HOV lane is a strategic decision and has to do with the answer to the following question: do we really want to promote sustainable mobility? If the answer is "yes", then the only problem is to find the appropriate combination of measures, so to maximize the benefits from the implementation of the HOV lane and at the same time to minimize the adverse effects (mainly environmental impact) in the near area. It must be mentioned that further research is needed in order to obtain more robust results concerning the traffic and environmental impact of the HOV lanes in urban areas. The use of traffic simulation and assignment models proved to be a very useful tool for the specific research.

\section{References}

[1] Victoria Transport Policy Institute (2005) Online TDM Encyclopedia, Downloadable from website http://www.vtpi.org/tdm

[2] Papaioannou, P. \& Georgiou, G., Are Traffic Demand Management (TDM) Measures a solution for traffic problems in urban areas? The Greek experience, Proc. of the 2nd KFB Int. Conf. on Urban Transport Systems, pp. 1-9, 1999.

[3] High Occupancy Vehicle (HOV) Lanes, www.konsult.leeds.ac.uk 
[4] Schijns, S. \& Eng, P., High occupancy vehicle lanes - worldwide lessons for European practitioners, Proc. of the $12^{\text {th }}$ Int. Conf. on Urban Transport and the Environment in the 21st Century, eds. C. A. Brebbia \& V. Dolezel, WITpress, Series: WIT Transactions on The Built Environment, Vol 89, pp. 181-193, 2006.

[5] ICARO, Increase of car occupancy through innovative measures and technical instruments, Main contractor: Universitat Fuer Bodenkultur Wien, EU project, 4th Framework, Transport RTD Programme, Research for Sustainable Mobility, 1999.

[6] Johnston, R.A. \& and Ceerla, R. The effects of new high-occupancy vehicle lanes on travel and emissions. Transportation Research Part A, 30(1), pp. 35-50, 1996.

[7] Dahlgren, J. High occupancy vehicle lanes: not always more effective than general purpose lanes, Transportation Research Part A, 32 (2), pp. 99-114, 1998.

[8] Yang, H. \& Huang, H-J. Car pooling and congestion pricing in a multilane highway with high-occupancy-vehicle lanes, Transportation Research Part $A, \mathbf{3 3}$, pp. 139-155, 1999.

[9] Dahlgren, J. High-occupancy/toll lanes: where should they be implemented? Transportation Research Part A, 36(3), pp. 239-255, 2002.

[10] General Secretariat of the National Statistical Service of Greece, Concise Statistical Yearbook 2007, Pireas, 2008.

[11] Laboratory of Transport Engineering, Faculty of Civil Engineering, Aristotle University of Thessaloniki, Research on trip characteristics in Thessaloniki Greater Area, Thessaloniki, 1989.

[12] Denco, Trademco, I. Aggelidis, Truth, Infodim, WS-Atkins, Steer Davies Gleave, Thessaloniki General Transportation Study, Organization for the Master Plan and Environmental Protection of Thessaloniki, Thessaloniki, 1999.

[13] Urban Transport Organisation of Thessaloniki (OASTH), www.oasth.gr

[14] Papaioannou, P. \& Georgiou, G. The implementation of an HOV lane in Thessaloniki: Impacts on traffic and the environment, Technika Chronika, 21(1-3), pp. 191-203, 2001.

[15] Taxiltaris C., Basbas, S., Nikolaou, K. \& Tzevelekis I. Environmental impact assessment of major pedestrianization schemes through the use of modelling techniques. Fresenius Environmental Bulletin, 11(10a), pp. 800805, 2002.

[16] Basbas S., Environmental evaluation of High Occupancy Vehicles (HOV) lanes, Fresenius Environmental Bulletin, 15(8a), pp. 791-797, 2006.

[17] Kitis, G. \& Stamos, I. Investigation for the implementation of an HOV lane in Thessaloniki, Diploma Thesis, Supervisor: Basbas, S., Faculty of Rural \& Surveying Engineering, Aristotle University of Thessaloniki, 2007. 